\title{
A note on the Upper Carboniferous bivalve Curvirimula Corvosa Rogers from Chimney Corner, Nova Scotia, Canada
}

\author{
Gary M. Vasey, Department of Applied Geology \\ University of Strathclyde, Glasgow, Scotland, U.K.
}

\begin{abstract}
The type specimens of Naiadites mytiloides Dawson and Curvirimula corvosa Rogers from the Riversdale Group of Chimney Corner have been re-examined. Both morphospecies can not be referred unequivocally to the genus Curvirimula Weir. The holotype of Naiadites mytiloides is so poorly preserved as to make this morphospecies almost undefinable, however, the types of Curvirimula corvosa are well preserved.

On a réexamié les specimens - types de Naiadites mytiloides Dawson et Curvirimula corvosa Rogers provenant du Groupe de Riversdale à Chimney Corner. On peut maintenant attribuer hors de tout doute ces deux espèces au genre Curvirimula Weir. La pitoyable preservation de l'holotype de Naiadites mytiloides rend cette especa morphologigue presque indéfinissable; par contre, les types de Curvirimula corvosa sont tous bien préservés.

[Traduit par le journal]
\end{abstract}

\section{INTRODUCTION}

Dawson (1894) described Naiadites mytiloides from Riversdale strata (Westphalian A) at Chimney Corner situated on the western shore of Cape Breton Island, Nova Scotia (Fig. 1). In Roger's (1965) revision of all of Dawson's nonmarine bivalve genera and species, the type specimen was relocated, described and figured. In addition, Curvirimula? corvosa Rogers was also described from the same locality. Rogers (1965) expressed doubts as to the generic affinities of both these morphospecies, but questioningly referred them to Naiadities and Curvirimula.

Much of the material examined by Rogers was deposited in museum collections; very few specimens were located that were referrable to Naiadites mytiloides or indeed, Curvirimula corvosa, though Dawson (1894, p. 125) stated that Naiadites mytiloides was abundant at the type locality.

The author has examined the types of Curvirimula corvosa and the type of Naiadites mytiloides as well as a large assemblage of shells from the type locality and from Nova Scotia Department of Mines \& Energy Boreholes DDNSCC-1 and DDNSCC-3.

\section{PRESERVATION}

At the type locality (Fig. 1), the shells occur in a medium- to dark-grey (N1.5MARITIME SEDIMENTS AND ATLANTIC GEOLOGY 20, 57-60 (1984)
2.5 grey value on the U.S. National Research Council Rock-Color chart (1965) silty shale of about $1.2 \mathrm{~m}$ thickness overlying a thin coal seam (probably the \#5 seam). The fauna appears to be limited to Curvirimula spp., Spirorbis sp., Carbonita spp., Pygocephalus sp.?, and there is a conspicuous absence of Naiadites on this horizon. Over 100 specimens of Curvirimula have been examined from the type locality and a horizon in the cores that, on the basis of its lithology, fauna and stratigraphic position, is considered to be the type horizon. The type horizon varies in thickness laterally, being $3.4 \mathrm{~m}$ thick in core DDNSCC-l and $1.8 \mathrm{~m}$ thick in core DDNSCC-3.

The holotypes of Naiadites mytiloides and Curvirimula corvosa both occur on the same slab of dark-grey silty shale (termed a sandy mudstone by Rogers (1965)) amongst much Curvirimula debris. The holotype of Naiadites mytiloides is poorly preserved with much of the anterior end, all of the ventral margin and part of the posterior end missing (Plate lc). The remaining part of the shell displays distinct curved, radial cracks (plate ld) and is therefore, unquestionably referrable to Curvirimula Weir (1960)

\section{SYSTEMATIC DESCRIPTION}

?Family MYALINIDAE Frech, 1891 emend. Newell, 1942

Genus CURVIRIMULA Weir, 1960 


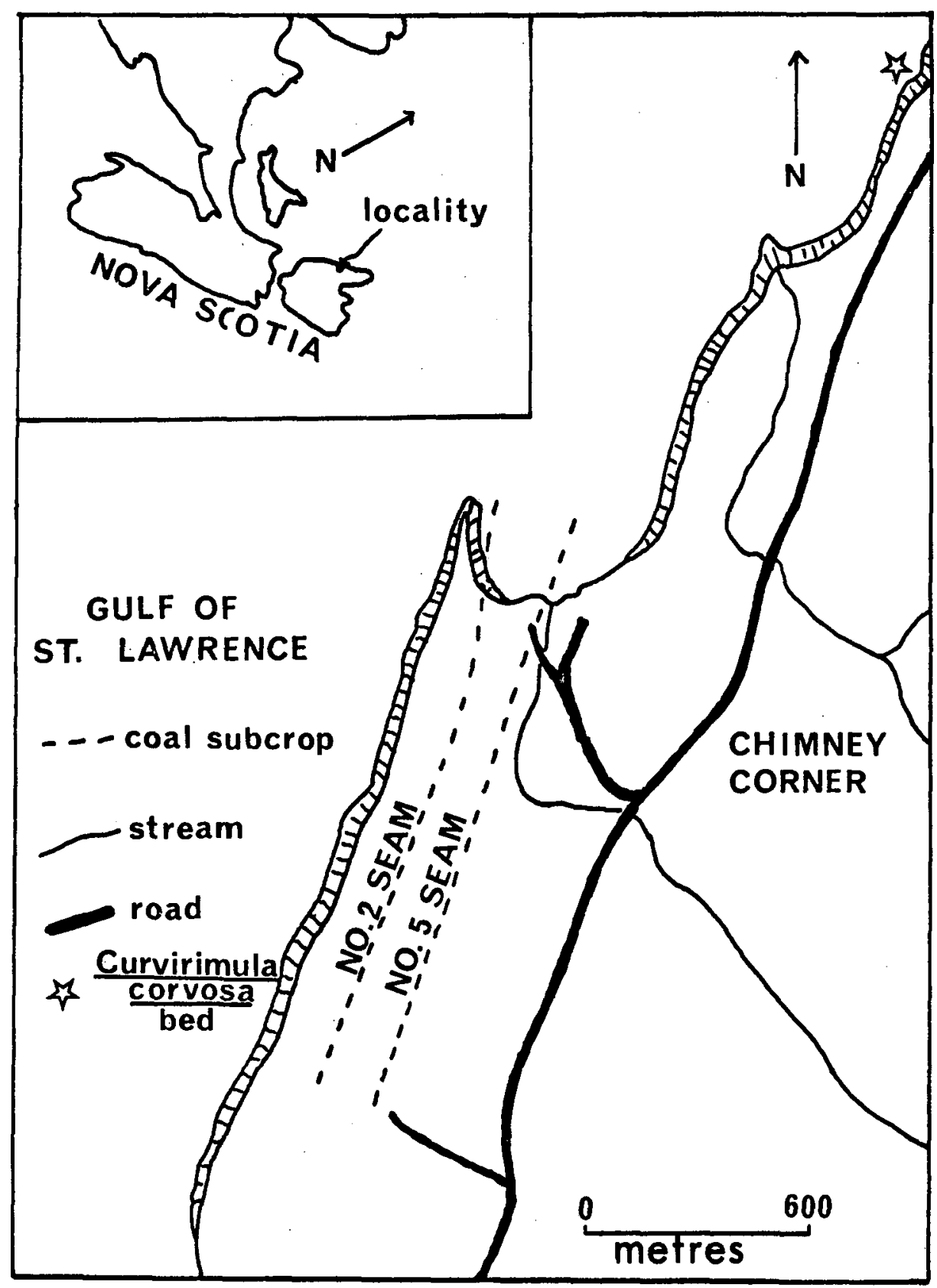

Fig. 1 - Sketch map of Chimney Corner and its geographic setting.

Curvirimula corvosa Rogers

Plate la, lb

Curvirimula? corvosa Rogers 1965, p. 680, Pl. 84, figures 29 and 30.

Diagnosis: shell small, subovate, thin and displaying short, curved radial cracks; umbo broadly inflated, on a level with the near straight dorsal margin; anterior end short, curving without angulation into the slightly convex ventral margin; angle $\gamma$ low, $B$ angle moderate; a faint umbonal swelling runs towards the posteroventral extremity, broadening and fading at about half height.

H/L - 85-90\%; DM/L - 65-70\%; A/L $18-25 \% ; \beta-\cdot 120 ; \gamma-55$.

(see Figure 2 for explanation of dimensions).

Type material and locality - RM 21163b (Redpath Museum, McGill University, Montreal) was designated the holotype and BM 4779510 (British Museum, London) 

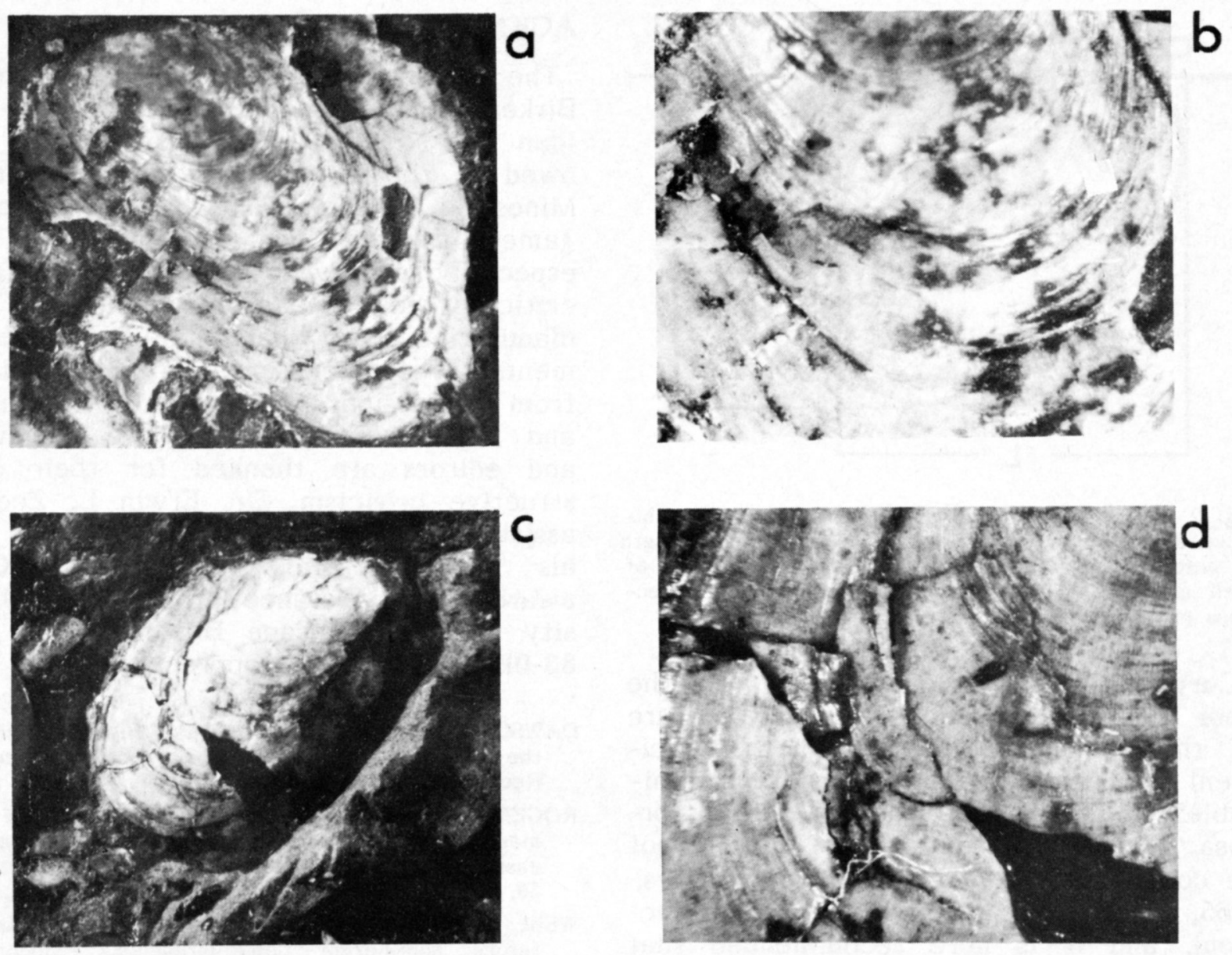

RLATE 1

a) Curvirimula? corvosa Rogers, Holotype, RM21163b, X8. Specimen is on the same slab of shale as Plate lc.

b) Enlargement of valve surface to show radial, curved cracks. Specimen as above. X16.

c) Naiadites mytiloides Dawson. Holotype, RM21l63a, X4.5. Note the incomplete nature of the ventral and posterior margins and anterior end.

d) Enlargement of valve surface to show radial, curved cracks. Specimen is as Plate lc. X16.

the paratype by Rogers (1965). The type locality is Chimney Corner, Cape Breton Island, Nova Scotia (Riversdale Group Westphalian A).

\section{DISCUSSION}

The holotype is slightly crushed along the upper ventral margin and also in the lower posterior region. Some growth lines are raised as curved nodes and this presumably represents the beginnings of more general crushing.

Rogers (1965) was in some doubt as to whether the species corvosa was referrable to the genus Curvirimula Weir, but in all aspects of external form this species should indeed be referred to that genus; because Naiadites mytiloides is in all preserved aspects of external form referrable to Curvirimula, it is here also assigned to that genus.

All species of Curvirimula from Nova Scotia display an external shell structure of radially aligned prisms between growth lines and, after some crushing, these are seen to produce the curved, radial cracks characteristic of this genus (Weir 1960). Both Curvirimula corvosa and $C$. mytiloides display this shell structure which is absent in other Nova Scotian Myalinio genera. 


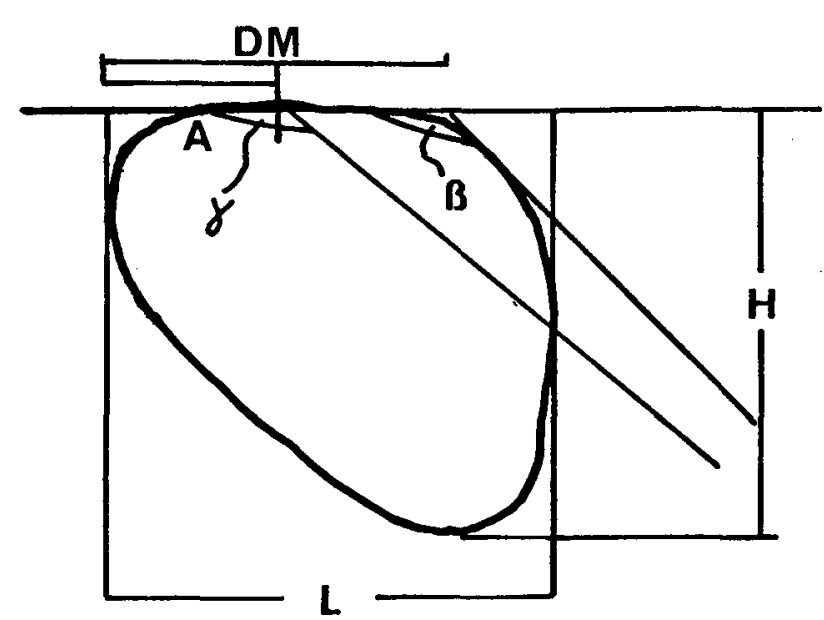

Fig. 2 - Explanation of measured dimensions on a bivalve shell; Angles $\alpha$ and $\beta$ are indicated. $A=$ length of anterior end, $L=$ length of shell, $H=$ height of shell and $\mathrm{DM}=$ length of the dorsal margin. Directions of measurement are shown above.

Curvirimula mytiloides, owing to the poor preservation and incomplete nature of the holotype (and only known specimen) is herein regarded as unrecognizable; it may be a synonym of C. corvosa. At the present time, this cannot be conclusively demonstrated (see Rogers, 1965, Pl. 32 for one possible reconstruction), and it is here recommended that the name C. mytiloides be restricted to the holotype. The type specimens of $\mathrm{C}$. corvosa are excellently preserved.

Owing to the distinct nature of the fauna and lithology, the Curvirimula corvosa horizon is easily traceable as a stratigraphic unit. Work is in progress on the detailed palaeontology of the Curvirimula corvosa bed and the shell shape variation within Curvirimula.

\section{ACKNOWLEDGEMENTS}

The author is grateful to Ms. Ingrid Birker of the Redpath Museum for the loan of several specimens. Thanks are owed to the Nova Scotia Department of Mines \& Energy for access to core; James Bingley and Kevin Gillis are especially thanked. Dr. R.M.C. Eagar critically read an early version of this manuscript and I thank him for his comments. The manuscript also benefitted from discussions with Drs. M.J. Rogers and W.H.C. Ramsbottom. The reviewers and editors are thanked for their constructive criticism. Dr. Erwin L. Zodrow assisted in the field and is thanked for his logistical aid. A N.E.R.C. Case award and assistance from the University College of Cape Breton (UCCB 8283-01) are gratefully appreciated.

DAWSON, J.W. 1894. Notes on the Bivalve Shells of the Coal-Formation of Nova Scotia. Canadian Record of Science, 5(3); pp. 117-134, 167.

ROGERS, M.J. 1965. A revision of the species of nonmarine Bivalve from the Upper Carboniferous of eastern North America. Journal of Paleontology 39, pp. 663-686.

WEIR, J. 1960-68. A monograph of British Carboniferous non-marine Lamellibranchia. Palaeontolographical Society, 99 (X-XIII), pp. 273-449.

Reviewers for author: M.J. Copeland N.J. Riley

Reviewers for journal: J. Pojeta, Jr. J. F. Riva 